\title{
Effects of Exogenous Abscisic Acid on Photosynthesis of Capsella bursa-pastoris Under Salt Stress
}

\author{
Yumei Tan ${ }^{1, a}$, Jianhua Li ${ }^{2, b}$, Huan Yao ${ }^{1, c}$, Zicheng Lu ${ }^{3, d}$, Maolin Chen ${ }^{4, e}$, \\ Mei Qing ${ }^{1, f}$ and Lijin Lin ${ }^{5, g^{*}}$
}

${ }^{1}$ College of Horticulture, Sichuan Agricultural University, Chengdu, Sichuan, China

2Sichuan Ya'an Municipal Product Quality Supervision \& Inspection Institute, Ya'an, Sichuan, China

${ }^{3}$ College of Agronomy, Sichuan Agricultural University, Chengdu, Sichuan, China

${ }^{4}$ College of Economics, Sichuan Agricultural University, Chengdu, Sichuan, China

${ }^{5}$ Institute of Pomology and Olericulture, Sichuan Agricultural University, Chengdu, Sichuan, China

a2229809882@qq.com, b710753781@qq.com, c272365026@qq.com, dizcheng666@qq.com, e3208585092@qq.com, f1115435013@qq.com, 9lj800924@163.com

${ }^{*}$ Corresponding author. Yumei Tan and Jianhua Li contributed equally to this work.

Keywords: Capsella bursa-pastoris; Abscisic acid; Photosynthesis; Chlorophyll

Abstract: A pot experiment was carried out to study the effects of exogenous abscisic acid (ABA) on the photosynthesis of Capsella bursa-pastoris under salt stress. Under salt stress, the chlorophyll $a$, chlorophyll $b$ and total chlorophyll contents of $C$. bursa-pastoris showed no obvious changes at low ABA concentrations ( 1 and $5 \mu \mathrm{mol} / \mathrm{L})$, but showed significant increases at high ABA concentrations $(10$ and $20 \mu \mathrm{mol} / \mathrm{L})$. The ABA treatments improved the chlorophyll $a / b$ ratio and increased the carotenoid content of $C$. bursa-pastoris compared with those of the control. Only the $20 \mu \mathrm{mol} / \mathrm{L}$ ABA dose significantly increased the Pn of C. bursa-pastoris compared with the control, while the other ABA concentrations showed no significant differences compared with the control. When the doses of ABA were 1 and $5 \mu \mathrm{mol} / \mathrm{L}$, the $\operatorname{Tr}$ and Gs values of $C$. bursa-pastoris showed no significant differences compared with their respective controls, while 10 and $20 \mu \mathrm{mol} / \mathrm{L}$ ABA doses significantly increased the $\mathrm{Tr}$ and Gs. The $\mathrm{Ci}$ and Vpdl under ABA treatments showed no significant differences compared with their respective controls. Thus, high ABA concentrations could increase the photosynthetic ability of C. bursa-pastoris.

\section{Introduction}

Land salinization is a worldwide problem, especially in China, where almost one-quarter of the cultivated land has been salinized, which seriously affects plant growth [1]. Soil salinization is becoming more serious, but its remediation is not easy [2]. Therefore, improving the salt tolerance of plants is important. Abscisic acid (ABA), a plant hormone, is a sesquiterpenoid compound with interesting physiological properties [3]. In plants, ABA is a 'stress-inducing factor' and is the first messenger to activate the expression of antidepressant genes [4]. It can activate the stress-resistant immune system in plants [5]. Under stressful conditions, the plant begins synthesizing ABA to enhance its own resistance [6]. Under salt stress, the biomass of grafted tomato seedlings is significantly greater than the control after the ABA content in leaves increases, which enhances the salt tolerance [7]. Thus, applying ABA to vegetable species may enhance their resistance to salt stress, but limited studies have addressed this hypothesis. Therefore, to enhance the photosynthesis ability of wild vegetable $C$. bursa-pastoris to salt stress, different concentrations of ABA were used to treat $C$. bursa-pastoris seedlings. The aim of this study was to determine the optimal ABA concentration for enhancing the photosynthesis ability of C. bursa-pastoris to salt stress. 


\section{Materials and Methods}

Materials. Seedlings of $C$. bursa-pastoris with five euphyllas were collected from the Chengdu Campus of Sichuan Agricultural University $\left(30^{\circ} 42^{\prime} \mathrm{N}, 103^{\circ} 51^{\prime} \mathrm{E}\right)$ in October 2015. The culture medium in the experiment was a 1:1 mixture of perlite and vermiculite.

Experimental Design. The culture medium was placed into polyethylene pots $(10 \mathrm{~cm}$ high, $10 \mathrm{~cm}$ in diameter), and three uniform seedlings of C. bursa-pastoris were transplanted into each pot. The plant seedlings were irrigated with $20 \mathrm{~mL}$ Hoagland nutrient solution (containing $50 \mathrm{mmol} / \mathrm{L} \mathrm{NaCl}$ ) [8] per pot every two days until the plants were harvested. When C. bursa-pastoris seedlings had grown for 15 days, five concentrations $(0,1,5,10$ and $20 \mu \mathrm{mol} / \mathrm{L})$ of $\mathrm{ABA}$ [9], with three replicates, were sprayed independently on the leaves of plants. The second and third ABA sprayings occurred at 18 days and 21 days after transplanting, respectively. At each spraying, $25 \mathrm{~mL}$ of ABA solution was used per pot, which just soaked the plants. 30 days after the last ABA spraying, the photosynthesis of each plant was determined using an LI-6400 portable photosynthesis meter (LI-COR Inc., USA). The photosynthetic parameters of the photosynthesis meter were a manual control $\mathrm{CO}_{2}$ concentration of $450 \mu \mathrm{mol} / \mathrm{mol}$, temperature of $20{ }^{\circ} \mathrm{C}$, and light intensity of $1,000 \mu \mathrm{mol} / \mathrm{m}^{2} / \mathrm{s}$. The determined photosynthetic parameters were net photosynthetic rate $(\mathrm{Pn})$, transpiration rate $(\mathrm{Tr})$, stomatal conductance (Gs), intercellular $\mathrm{CO}_{2}$ concentration $(\mathrm{Ci})$ and leaf vapor pressure deficit (VpdL), and each plant was analyzed three times. Then, the upper mature leaves of C. bursa-pastoris were collected to determine the photosynthetic pigment (chlorophyll $a$, chlorophyll $b$, total chlorophyll and carotenoid) contents [10].

Statistical Analyses. Statistical analyses were performed using SPSS 13.0 statistical software (IBM, Chicago, IL, USA). Data were analyzed by a one-way analysis of variance with least significant difference at a 5\% confidence level.

\section{Results}

Photosynthetic pigment in $\boldsymbol{C}$. bursa-pastoris. When the concentrations of ABA were 1 and 5 $\mu \mathrm{mol} / \mathrm{L}$, there were no significant differences in the chlorophyll $a$, chlorophyll $b$ and total chlorophyll contents of C. bursa-pastoris compared with their respective controls (Table 1). At doses of 10 and 20 $\mu \mathrm{mol} / \mathrm{L}$ ABA significantly increased the chlorophyll $a$, chlorophyll $b$ and total chlorophyll contents of C. bursa-pastoris increased compared with their respective controls, and $20 \mu \mathrm{mol} / \mathrm{L} \mathrm{ABA}$ produced the maximum levels, which increased the chlorophyll $a$, chlorophyll $b$ and total chlorophyll contents by $13.62 \%, 13.90 \%$ and $17.47 \%$, respectively, compared with their respective controls. The ABA treatments improved the chlorophyll $a / b$ ratio of $C$. bursa-pastoris compared with the control, with an order of $10 \mu \mathrm{mol} / \mathrm{L}$ ABA $>5 \mu \mathrm{mol} / \mathrm{L} \mathrm{ABA}>1 \mu \mathrm{mol} / \mathrm{L} \mathrm{ABA}>20 \mu \mathrm{mol} / \mathrm{L}$ ABA $>0 \mu \mathrm{mol} / \mathrm{L}$ ABA (Table 1). The ABA treatments increased the carotenoid content of $C$. bursa-pastoris compared with that of the control (Table 1). When the doses of ABA were 1, 5, 10 and $20 \mu \mathrm{mol} / \mathrm{L}$, the carotenoid contents increased by 7.53\% $(p<0.05), 10.24 \%(p<0.05), 15.36 \%(p<0.05)$ and $17.47 \%(p<0.05)$, respectively, compared with that of the control.

Table 1 Photosynthetic pigment content in Capsella bursa-pastoris

\begin{tabular}{|c|c|c|c|c|c|}
\hline $\begin{array}{c}\text { ABA } \\
\text { concentrations } \\
(\mu \mathrm{mol} / \mathrm{L})\end{array}$ & $\begin{array}{c}\text { Chlorophyll } a \\
(\mathrm{mg} / \mathrm{g})\end{array}$ & $\begin{array}{c}\text { Chlorophyll } b \\
(\mathrm{mg} / \mathrm{g})\end{array}$ & $\begin{array}{c}\text { Total } \\
\text { chlorophyll } \\
(\mathrm{mg} / \mathrm{g})\end{array}$ & $\begin{array}{c}\text { Chlorophyll } \\
a / b\end{array}$ & $\begin{array}{c}\text { Carotenoid } \\
(\mathrm{mg} / \mathrm{g})\end{array}$ \\
\hline 0 & $1.578 \pm 0.010 \mathrm{~b}$ & $0.478 \pm 0.027 \mathrm{c}$ & $2.056 \pm 0.035 \mathrm{~b}$ & 3.301 & $0.332 \pm 0.004 \mathrm{~d}$ \\
\hline 1 & $1.616 \pm 0.080 \mathrm{~b}$ & $0.488 \pm 0.009 \mathrm{bc}$ & $2.104 \pm 0.077 \mathrm{~b}$ & 3.311 & $0.357 \pm 0.015 \mathrm{c}$ \\
\hline 5 & $1.659 \pm 0.008 \mathrm{~b}$ & $0.495 \pm 0.012 \mathrm{bc}$ & $2.154 \pm 0.004 \mathrm{~b}$ & 3.352 & $0.366 \pm 0.005 \mathrm{bc}$ \\
\hline 10 & $1.772 \pm 0.080 \mathrm{a}$ & $0.521 \pm 0.031 \mathrm{ab}$ & $2.293 \pm 0.106 \mathrm{a}$ & 3.401 & $0.383 \pm 0.019 \mathrm{ab}$ \\
\hline 20 & $1.793 \pm 0.069 \mathrm{a}$ & $0.543 \pm 0.030 \mathrm{a}$ & $2.336 \pm 0.099 \mathrm{a}$ & 3.302 & $0.390 \pm 0.013 \mathrm{a}$ \\
\hline
\end{tabular}

Values are means $( \pm \mathrm{SE})$ of three replicate pots. Different lowercase letters within a column indicate significant differences based on a one-way analysis of variance in SPSS 13.0 followed by the least significant difference test $(p<0.05)$. 
Photosynthetic characteristics of $\boldsymbol{C}$. bursa-pastoris. When the doses of ABA were 1, 5 and 10 $\mu \mathrm{mol} / \mathrm{L}$, the Pn values of $C$. bursa-pastoris showed no significant differences compared with the control (Table 2). However, a $20 \mu \mathrm{mol} / \mathrm{L}$ ABA dose increased the Pn of C. bursa-pastoris by $12.10 \%$ $(p<0.05)$ compared with that of the control. When the doses of ABA were 1 and $5 \mu \mathrm{mol} / \mathrm{L}$, the $\operatorname{Tr}$ and Gs values of $C$. bursa-pastoris showed no significant differences compared with their respective controls (Table 2). However, 10 and $20 \mu \mathrm{mol} / \mathrm{L} \mathrm{ABA}$ doses increased the $\operatorname{Tr}$ by $45.52 \%(p<0.05)$ and $55.97 \%(p<0.05)$, respectively, compared with the control, and increased the Gs by $66.02 \%(p<0.05)$ and $71.09 \%(p<0.05)$, respectively. The $\mathrm{Ci}$ and $\mathrm{Vpdl}$ values of the ABA treatments showed no significant differences compared with their respective controls (Table 2). Thus, high ABA concentrations could increase the Pn, Tr and Gs of C. bursa-pastoris, but had no obvious effects on its $\mathrm{Ci}$ and Vpdl.

Table 2 Photosynthetic characteristics of Capsella bursa-pastoris

\begin{tabular}{|c|l|l|l|l|l|}
\hline $\begin{array}{c}\mathrm{ABA} \\
\text { concentrations } \\
(\mu \mathrm{mol} / \mathrm{L})\end{array}$ & \multicolumn{1}{|c|}{$\begin{array}{c}\mathrm{Pn} \\
\left(\mu \mathrm{mol} \mathrm{CO} / \mathrm{m}^{2} / \mathrm{s}\right)\end{array}$} & $\begin{array}{c}\mathrm{Tr} \\
\left(\mathrm{mmol} \mathrm{H} \mathrm{O} / \mathrm{m}^{2} / \mathrm{s}\right)\end{array}$ & $\begin{array}{c}\mathrm{Ci} \\
(\mu \mathrm{mol} \mathrm{CO} / \mathrm{mol})\end{array}$ & $\begin{array}{c}\mathrm{Gs} \\
\left(\mathrm{mol} \mathrm{H}_{2} \mathrm{O} / \mathrm{m}^{2} / \mathrm{s}\right)\end{array}$ & $\begin{array}{c}\mathrm{VpdL} \\
(\mathrm{kPa})\end{array}$ \\
\hline 0 & $15.45 \pm 0.92 \mathrm{~b}$ & $2.68 \pm 0.50 \mathrm{~b}$ & $343.20 \pm 11.06 \mathrm{ab}$ & $0.256 \pm 0.050 \mathrm{~b}$ & $0.953 \pm 0.012 \mathrm{ab}$ \\
\hline 1 & $15.81 \pm 0.67 \mathrm{~b}$ & $2.37 \pm 0.84 \mathrm{~b}$ & $338.28 \pm 8.81 \mathrm{~b}$ & $0.250 \pm 0.057 \mathrm{~b}$ & $0.951 \pm 0.050 \mathrm{ab}$ \\
\hline 5 & $16.08 \pm 0.37 \mathrm{~b}$ & $2.24 \pm 0.89 \mathrm{~b}$ & $335.89 \pm 8.43 \mathrm{~b}$ & $0.238 \pm 0.042 \mathrm{~b}$ & $0.933 \pm 0.011 \mathrm{~b}$ \\
\hline 10 & $16.28 \pm 0.09 \mathrm{ab}$ & $3.90 \pm 0.14 \mathrm{a}$ & $355.54 \pm 10.84 \mathrm{a}$ & $0.425 \pm 0.008 \mathrm{a}$ & $0.968 \pm 0.052 \mathrm{ab}$ \\
\hline 20 & $17.32 \pm 0.76 \mathrm{a}$ & $4.18 \pm 0.52 \mathrm{a}$ & $357.77 \pm 11.39 \mathrm{a}$ & $0.438 \pm 0.079 \mathrm{a}$ & $0.999 \pm 0.017 \mathrm{a}$ \\
\hline
\end{tabular}

Values are means $( \pm$ SE) of three replicate pots. Different lowercase letters within a column indicate significant differences based on a one-way analysis of variance in SPSS 13.0 followed by the least significant difference test $(p<0.05)$.

\section{Discussion}

Salt stress destroys the dynamic balance between the synthesis and degradation of the chlorophyll $a$ and chlorophyll $b$ in plant leaves, resulting in decreased chlorophyll $a$ and chlorophyll $b$ contents, which inhibits photosynthesis [11]. ABA can increase the chlorophyll and carotenoid contents in plant leaves [12]. In this experiment, the chlorophyll $a$, chlorophyll $b$ and total chlorophyll contents of C. bursa-pastoris showed no obvious changes at low ABA concentrations ( 1 and $5 \mu \mathrm{mol} / \mathrm{L}$ ), but showed significant increases at high ABA concentrations (10 and $20 \mu \mathrm{mol} / \mathrm{L})$. The ABA treatments improved the chlorophyll $a / b$ ratio and increased the carotenoid content of $C$. bursa-pastoris compared with those of the control, which showed benefits to the photosynthesis of C. bursa-pastoris. When the plants are subjected to salt stress, the stomata of leaves will change to adapt to the stressful environment [13], such as the stomata closing due to leaf water loss induced by salt stress [13-14]. The stomatal closure leads to the decrease in the $\mathrm{Ci}$ and $\mathrm{Pn}$ [14]. In this experiment, only the 20 $\mu \mathrm{mol} / \mathrm{L}$ ABA dose significantly increased the Pn of C. bursa-pastoris compared with the control, while the other ABA concentrations showed no significant differences compared with the control. When the doses of ABA were 1 and $5 \mu \mathrm{mol} / \mathrm{L}$, the $\operatorname{Tr}$ and Gs values of $C$. bursa-pastoris showed no significant differences compared with their respective controls, while 10 and $20 \mu \mathrm{mol} / \mathrm{L}$ ABA doses significantly increased the $\mathrm{Tr}$ and Gs. The $\mathrm{Ci}$ and Vpdl under ABA treatments showed no significant differences compared with their respective controls. Thus, high ABA concentrations could increase the photosynthetic ability of $C$. bursa-pastoris, which may be related to the low sensitivity of $C$. bursa-pastoris to low ABA concentrations.

\section{Conclusions}

Under salt stress, the chlorophyll $a$, chlorophyll $b$ and total chlorophyll contents of $C$. bursa-pastoris showed no obvious changes at low ABA concentrations ( 1 and $5 \mu \mathrm{mol} / \mathrm{L})$, but showed significant increases at high $\mathrm{ABA}$ concentrations $(10$ and $20 \mu \mathrm{mol} / \mathrm{L})$. The ABA treatments improved the 
chlorophyll $a / b$ ratio and increased the carotenoid content of $C$. bursa-pastoris compared with those of the control. Only the $20 \mu \mathrm{mol} / \mathrm{L} \mathrm{ABA}$ dose significantly increased the Pn of C. bursa-pastoris compared with the control, while the other ABA concentrations showed no significant differences compared with the control. When the doses of ABA were 1 and $5 \mu \mathrm{mol} / \mathrm{L}$, the $\operatorname{Tr}$ and Gs values of $C$. bursa-pastoris showed no significant differences compared with their respective controls, while 10 and $20 \mu \mathrm{mol} / \mathrm{L} \mathrm{ABA}$ doses significantly increased the $\mathrm{Tr}$ and Gs. The $\mathrm{Ci}$ and Vpdl under ABA treatments showed no significant differences compared with their respective controls. Thus, high ABA concentrations could increase the photosynthetic ability of $C$. bursa-pastoris.

\section{Acknowledgements}

This work was financially supported by the 2016 Innovation Training Program of University Student (201610626032) and the Application Infrastructure Project of Science and Technology Department of Sichuan Province (2016JY0258).

\section{References}

[1] H.P. Zhou, L.X. Zhang, F. Yu and P. Li: Modern agricultural science and technology Vol. 36 (2007), p. 159.

[2] J. Levitt: Response of plants to environmental stresses. Vol. II. Water, radiation, salt, and other stresses (New York: Academic Press 1980).

[3] M.L.W. Knetsch, M. Wang, B.E. Snaar-Jagalska and S. Heimovaara-Dijkstra: The Plant Cell Vol. 8 (1996), p. 1061.

[4] B.E. Anderson, J.M. Ward and J.I. Schroeder: Plant Physiology Vol. 104 (1994), p. 1177.

[5] S.X. Wang, K.Q. Peng, L.T. Xiao and S.T. Xia: Plant Physiology Communications Vol. 39 (2003), p. 413.

[6] K. Ikegami, M. Okamoto, M. Seo and T. Koshiba: Journal of Plant Research Vol. 122 (2009), p. 235.

[7] S.F. Chen, Y.L. Zhu, Y.L. Liu and S.J. Li: Acta Horticulturae Sinica Vol. 32 (2005), p. 609.

[8] X.L. Yu, B.J. Zhang and X.P. Wang: Journal of Anhui Agricultural Sciences Vol. 40 (2012), p. 8864.

[9] J. Wang, L. Lin, L. Luo, M. Liao, L. Lv, Z. Wang, D. Liang, H. Xia, X. Wang, Y. Lai and Y. Tang: Environmental Monitoring and Assessment Vol. 188 (2016), p. 182.

[10] Z.B. Hao, J. Chang and Z. Xu: Plant Physiology Experiment (Harbin Institute of Technology Press, China 2004).

[11] Z.H. Liu, L.R. Shi and L.R. Bai: Journal of Plant Physiology and Molecular Biology Vol. 33 (2007), p. 165.

[12] Y.H. Huang, R.S. Tang, X.Q. Ye and H.Y. Tong: Journal of Triticeae Crops Vol. 29 (2009), p. 503.

[13] H.X. Chen, W.J. Li, S.Z. An and H.Y. Gao: Journal of Plant Physiology Vol. 161 (2004), p. 257.

[14] P.C. Bethke and M.C. Drew: Plant Physiology Vol. 99 (1992), p. 219. 